\title{
Location, location, location - Considering relative catchment location to understand subsurface losses
}

\author{
Melike Kiraz ${ }^{1}$, Gemma Coxon ${ }^{1}$, and Thorsten Wagener $^{2}$ \\ ${ }^{1}$ University of Bristol \\ ${ }^{2}$ University of Potsdam
}

September 24, 2021

\begin{abstract}
The analysis of large samples of hydrologic catchments is regularly used to gain understanding of hydrologic variability and controlling processes. Several studies have pointed towards the problem that available catchment descriptors (such as mean topographic slope or average subsurface properties) are insufficient to capture hydrologically relevant properties. Here, we test the assumption that catchment location, i.e. the relative properties of catchments in relation to their surrounding neighbours, can provide additional information to reduce this problem. We test this idea in the context of Great Britain for a widely discussed problem, that of catchment water balance errors due to subsurface losses. We test three hypotheses while considering different locational aspects (1) location to coast, (2) location next a relevant neighbour and (3) location within the drainage basin, utilizing only basic and widely available geological and topographical information. We find that subsurface losses from catchments with a highly permeable geology connection to the coast are in order of $20 \%$ water balance error. We define a simple topographic-geologic index that is able to partially explain water balance issues between neighbours of highly permeable catchments. The results imply that location, geology and topography combine to define the differences of water balances of UK catchments compared to what we would expect from their climatic setting alone. The simple index defined here can easily be derived globally and tested regarding its wider applicability.
\end{abstract}

Melike Kiraz ${ }^{1 *}$, Gemma Coxon ${ }^{2}$, and Thorsten Wagener ${ }^{1,3}$

${ }^{1}$ University of Bristol, Civil Engineering, Bristol, United Kingdom

${ }^{2}$ University of Bristol, School of Geographical Sciences, Bristol, United Kingdom

${ }^{3}$ University of Potsdam, Institute for Environmental Science and Geography, Germany

*Corresponding author: Melike Kiraz (melike.kiraz@bristol.ac.uk)

Key Words

Comparative hydrology, water balance, topography, geology, location, Great Britain, subsurface hydrology, CAMELS-GB

\section{Hosted file}

Main Text.docx available at https://authorea.com/users/435204/articles/538384-locationlocation-location-considering-relative-catchment-location-to-understand-subsurfacelosses

\section{Hosted file}


Acknowledgments . docx available at https ://authorea.com/users/435204/articles/538384-locationlocation-location-considering-relative-catchment-location-to-understand-subsurfacelosses

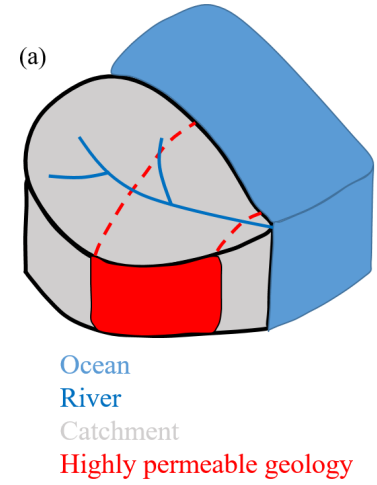

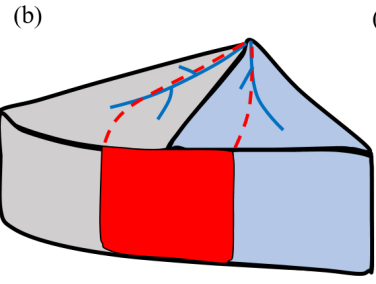

River Catchment

Highly permeable geology (c)

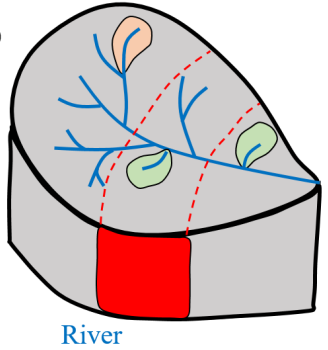

Drainage basin

Upper catchment

Highly permeable geology (a)

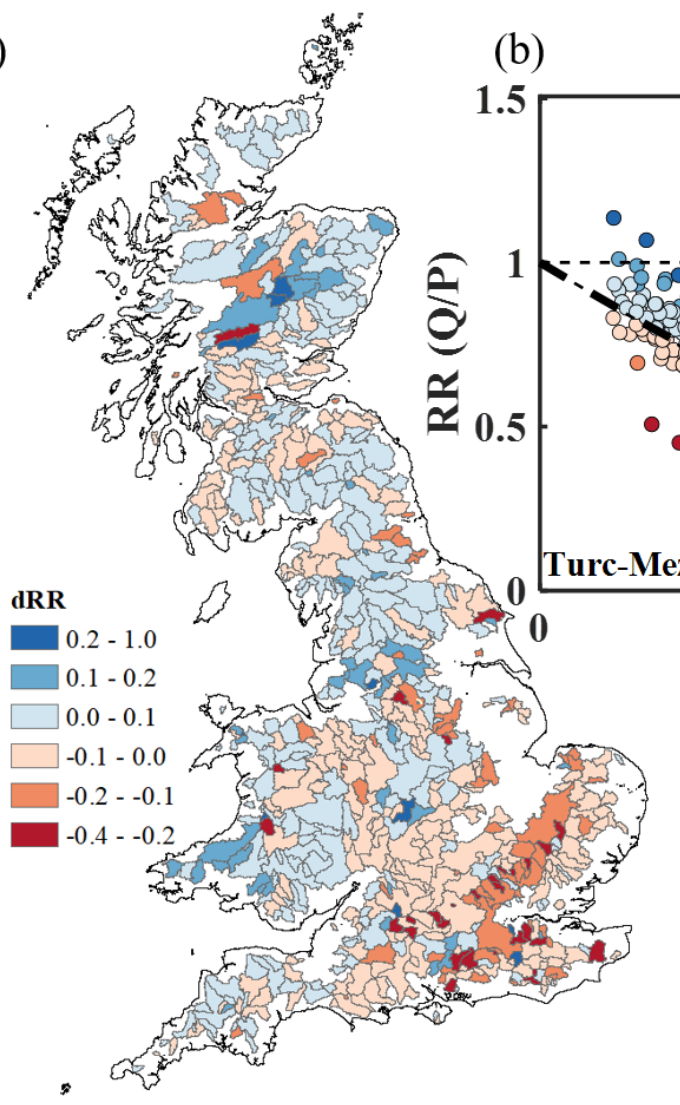

(b)

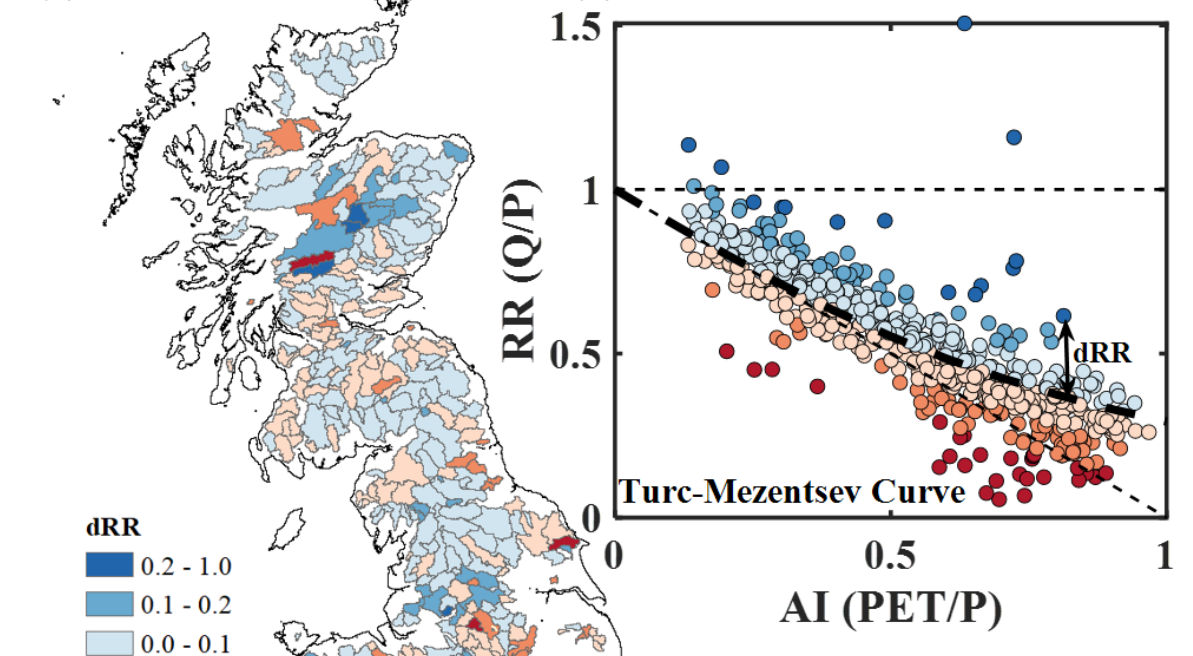



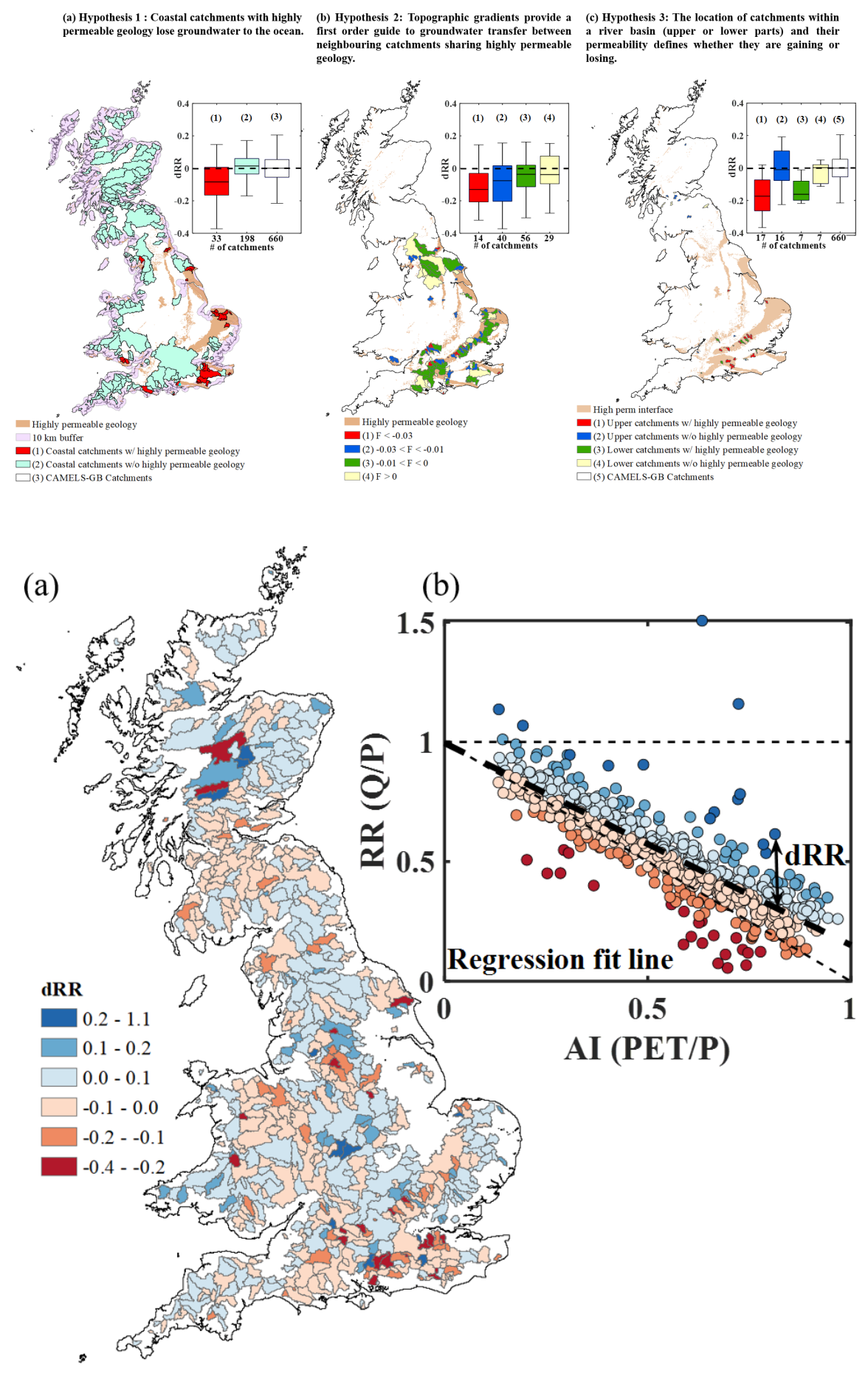


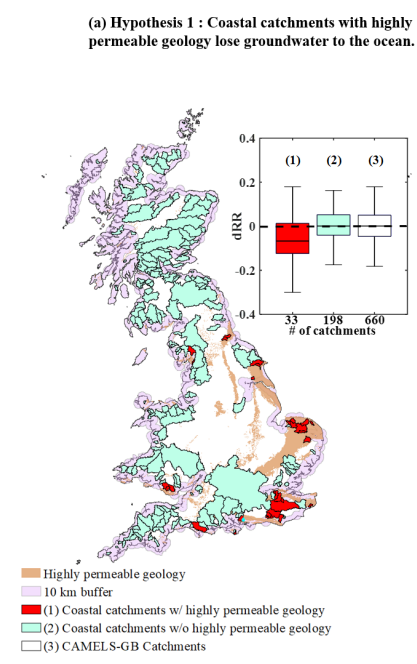

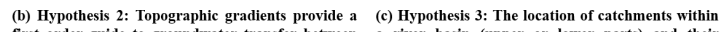
first order guide to groundwater transfer between a river basin (upper or lower parts) and their
neighbouring catchments sharing highly permeable permeability defines whether they are gaining or geology.
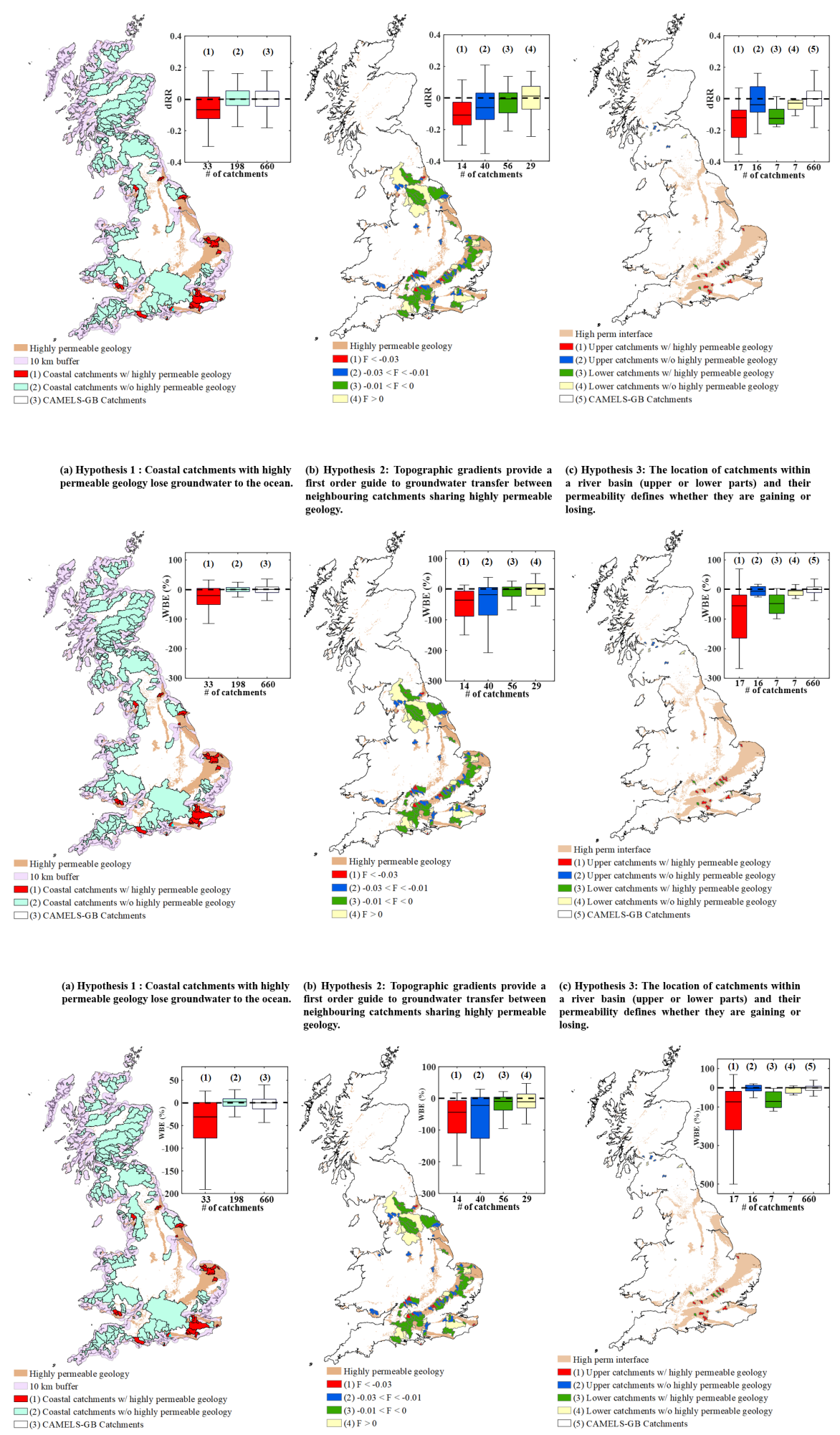

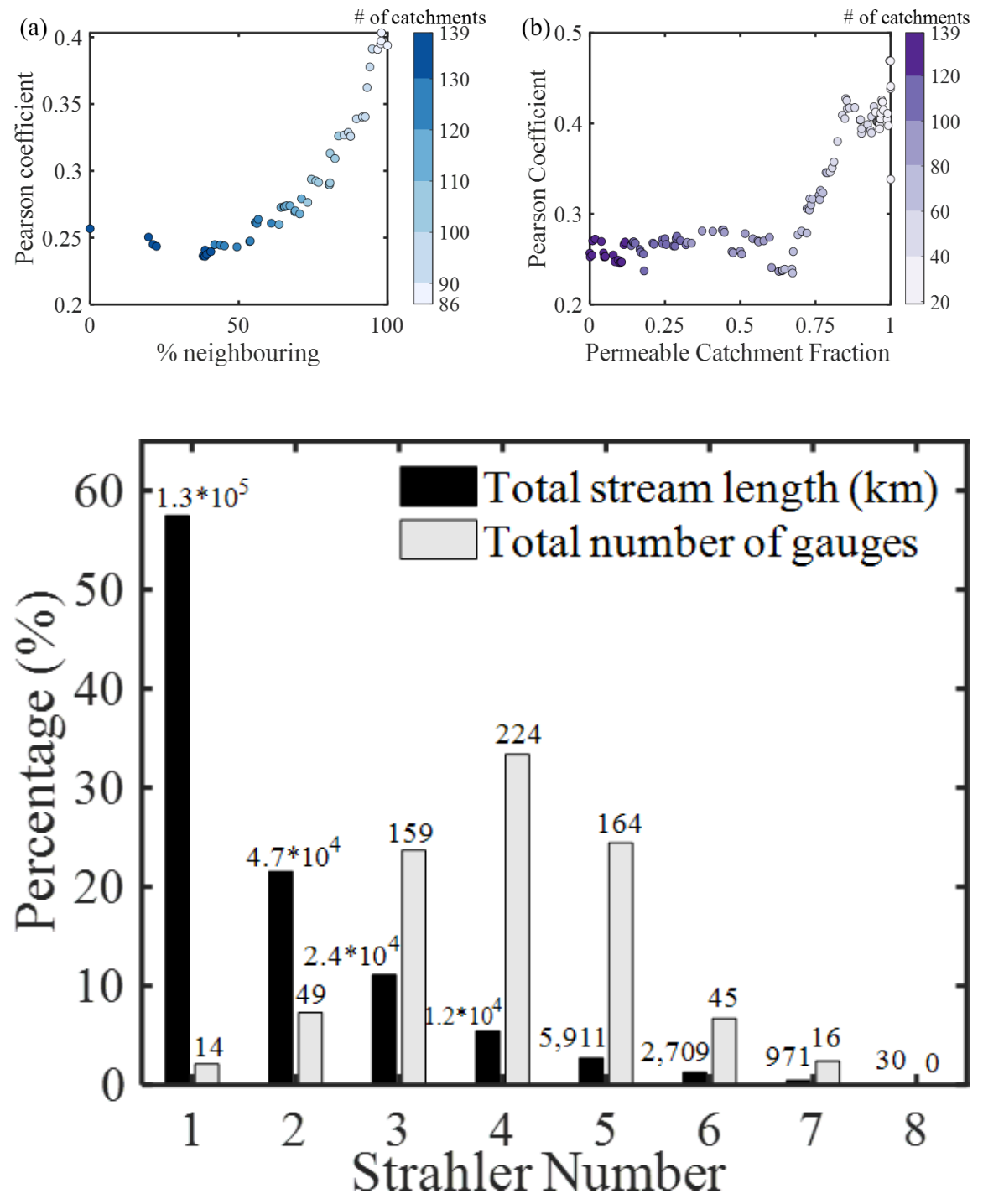